\title{
A Study of the Effect of Combining Multi-Sensor Signals and Cutting Chip Color on Tool Life Prediction
}

\author{
Shao-Hsien Chen ${ }^{1 *}$ and Min-Sheng Gao ${ }^{2}$ \\ 1 Graduate Institute of Precision Manufacturing, National Chin-Yi University of Technology, \\ No.57, Sec. 2, Zhongshan Rd., Taiping Dist., Taichung 41170, Taiwan \\ 2 Department of Mechanical Engineering, National Chin-Yi University of Technology, \\ * Correspondence: e6036@ncut.edu.tw
}

\begin{abstract}
Often, engineers with machining experience often judge machining state and tool life according to chips' features. Engineers' experience is digitized in this study. During the cutting process, the cutting tool coming in contact with the workpiece produces a shear zone, which causes plastic deformation and shear slip. The chips closest to the shear zone can directly show the state of the tool and workpiece when the material is SKD61. This study used chip color, vibration, and current signal integration for prediction of machining state and cutting tool life. When the cutting tool wears increased, the chip surface color changed in the following way: purple $\rightarrow$ purple blue $\rightarrow$ blue $\rightarrow$ cyan, or even green and yellow. When the cutting tool was in the accelerating wear phase, the color change was particularly obvious. The Back-Propagation Levenberg-Marquardt (BP-LM) predictive methodology was used to compare the predictive ability of voltage, vibration signal, and chip color. The Mean Absolute Percentage Error (MAPE) for the voltage signal was $12.28 \%$, for the vibration signal it was $11.38 \%$, and for the chip color combined with multi-sensor characteristics it was $7.85 \%$. The MAPE of the chip color was the smallest. Using the General Regression Neural Network (GRNN) methodology, the MAPE for the voltage signal was $10.74 \%$, for the vibration signal $7.96 \%$, and for the chip color combined with multi-sensor characteristics was $6.59 \%$. The MAPE of the chip color was the smallest. Obviously, the chip color combined with multi-sensor signals provided better predictive results than the vibration signal or voltage signal alone. There is currently no research on the usefulness of monitoring chip color for tool life prediction.
\end{abstract}

Keywords: Cutting Tool Wear; Chip Color; Color Correction; Multi-sensor

\section{Introduction}

Cutting tools dislocate the workpieces rapidly during the machining process, generating a large amount of heat, which is transferred to the chips, inducing a color change on the chip surface. Therefore, the contributions and research objectives of this study were: (1) to establish the features of chips' chromatic conversion and a calibration methodology, (2) to evaluate the relationship between chip color and tool wear, (3) to compare different prediction methodologies and measurement signals, and (4) to investigate the influence of chip color on tool wear. The signals measured were chip color, vibration, and voltage. Pearson's Correlation Coefficient (PCC) was used for feature selection, and BP and GRNN were used for prediction and comparison. Finally, our aim was to obtain a new tool life prediction methodology and improve production efficiency. Previous researchers considered process parameters such as the acoustic emission (AE) signal [1,2], vibration amplitude [3,41], motor currents [5-7], cutting torque [8], and thrust force $[9,10]$ as indicators of tool wear and failure [11,12]. Chip color can be evaluated close to the cutting area, and this measure can integrate those of current and vibration for multi-sensor vehicle measurements and prediction.

The spindle motor current and feed driver current are closely related to the forces involved in machining, similar to the torque [13], since both show the amount of 
consumed power in the cutting process. Driver current monitoring is the best approach to acquire signals without sensors, because in this way the machine is not modified, even when current sensors are used [14,15]. The discussed feature selection and classification methods used the current signals of the spindle motor to monitor the drilling process. The non-invasive Hall effect sensor was used to measure the motor current. The wavelet coefficients of the current signal were calculated first, and the subset of these coefficients was selected as initial diagnostic characteristics based on their ability to identify each pair of fault categories [16]. The method used nonlinear RPNN for paired feature classification. The experimental data proved that the average success rate of the proposed classification method was 93\%. It's discussed a monitoring method based on neural network and spindle motor power sensors to test the chip processing state during drilling [4]. Therefore, these two components allowed monitoring the chip processing state in the drilling process. The spindle motor power was tested by an alternating-current $(\mathrm{AC})$ spindle motor driving system, and the drilling torque could be measured indirectly. The difference between square and average values, the mean absolute deviation, and the gradient could be measured according to the spindle motor power as feature vectors. Motor power and motor current are the main sources of information during metal cutting, and their values are associated with changes at the cutting area, especially for TW. In theory, it is expected that with the increase of cutting TW, the CFs are enhanced, and this directly affects the cutting power and current $[17,56]$. Even current sensors appeared promising for multiple optimizations, such as TCM, FW, and tool breakage monitoring in past studies [18-23].

After defining factors including machine tools, workpieces, and machining methods, the main factors influencing cutting forces and vibration are cutting factors, tool wear, tool wear cutting force, and cutting temperature during the metal cutting process [24-26]. As tool wear increases, the cutting force and power increase too $[27,28]$. A study reported a mathematical model of the force of face milling, taking into account machining parameters and tool wear [29,55]. In this work, the influence of cutting conditions and wear on the cutting force on the back surface of a tooth cutter was shown. Promising for monitoring cutting operations is the control of the cutting power $[30,31]$. The techniques more frequently used are related to torque, force, and feed rate, since cutting forces increase when tool wear increases [32,33]. A mathematical model of the power of the main drive, which can be used to control the milling conditions in the process of wear of the cutting tool was presented. At the end of the tool's lifetime, a rapid increase of radial and axial cutting forces was observed, in particular for coated cutting tools, whereas this was not observed with uncoated tools. The good agreement between the coated-tool life results obtained from normalized cutting force data and nose wear measurements demonstrated that on-line examination of the wear behavior of multi-layer ceramic-coated tools can be carried out by monitoring the radial and axial force signals [34,54].

A study used an image processing technique to analyze TW during turning of AISI 4340 steel under cutting conditions leading to catastrophic failure of the tool and stated that this approach was successful in identifying sharp, semi-dull and dull cutting tools [35]. Another study used EN24T to determine the extent of FW via image processing [36]. Image processing and neural networks were also used to predict tool life during turning of $\mathrm{C} 45$ steel. This approach provided results with a large error because of excessive TW; the accuracy of the prediction was satisfying and proper for industrial applications [37]. Barreiro et al. used a digital image processing method to determine the life of a cutting tool. Their findings allow reducing tool costs by using a new wear criterion [38]. Another study proposed an online wear-monitoring system with geometric descriptors from linear images. This approach classifies wear as low, medium, and high [39]. 
Research has identified that tool wear affects chip color. The parameters of surface roughness, cutting tool wear, and chip morphology of cutting steel AISI 4340 steel can be evaluated to estimate processing costs. ANOVA showed that the dominant parameters influencing surface roughness were the feed rate per revolution, followed by the cutting speed. The surface roughness value increased with the feed rate per revolution, whereas the cutting speed showed an inverse relationship [40]. Chip color was analyzed to determine the cutting temperature in high-speed end milling of die steel AISI H13. This study used a ball cutter for high-speed end milling [42]. The color of the chips and the temperature at different spindle speeds and depths of cut were determined. The result showed that the cutting temperature rose as the spindle speed and depth of the cut increased. This study used the chip color, vibration, and current signal integration for predicting tool wear. Although much research has been carried out on the effects of vibration and current signal on tool wear, no studies have focused on the relationship between tool wear and chip [43-46].

This publication presents a simple and effective approach to determine tool wear depending on chromaticity coordinate points for the chip color. Therefore, an experimental milling setup was used integrating a synchronized sensor system include an accelerometer, voltage sensor, and chromaticity coordinate points as Analysis and prediction. Comparison of outputting tool wear using three types of input signals(voltage, vibration signal, and chip color) and two prediction methods(BP-LM and GRNN). This setup not only enables the analysis of the tool wear but also the monitoring of the accuracy of the workpiece. This study analyzed chip color to estimate tool life and compared its prediction ability to that of vibration and current measures. We used the prediction methods of BP and GRPP; the expected error was within $10 \%$.

\section{Cutting principle and wear}

\subsection{Cutting tool wear}

In general studies of cutting, the estimation of tool life is mostly done using the Taylor tool life equation. In 1906, Taylor proposed a relationship between tool life and cutting speed. This is a machining benchmark, mainly referred to ISO 8688-2 standards. The relationship between cutting speed $(V)$ and tool life $(T)$ can be expressed by the following equation:

$V c T^{n}=C$.

where $V_{c}$ is cutting speed, $T$ is the tool life, i.e., the tool's actual cutting time, $\mathrm{n}$ is an index referred to the cutting tool and workpiece material conditions, $C$ is a constant of the machining process; besides cutting speed, the machining parameters include feed per tooth and cutting depth. If all the machining parameters are considered in the tool life equation, using Taylor's tool life formulas to establish the cutting test experiment parameters [57,58], a complete tool life equation can be obtained and expressed as follows:

$V c T^{n} f_{z}^{a} a p^{b}=C$.

\subsection{Die steel SKD61 Is difficult to cut}

SKD61 is a hot-working tool steel with alloying elements such as Chromium (Cr), Molybdenum (Mo), and Vanadium (Va); it has good ductility, wear resistance, and resistance to high-temperature fatigue. The composition and physical characteristics of SKD61 are shown in Table 1; it is suitable for long-term operation in a hot environment. The increase of temperature will improve its mechanical properties; in addition, the higher the hardness of the mold, the longer its service life, as the mold 
can bear sudden temperature changes and it is unlikely to deform. Therefore, die steel is widely used in the mold industry. This material is applicable to $\mathrm{Al}, \mathrm{Mg}, \mathrm{Zn}$, and $\mathrm{Cu}$ alloy compression molds. Hand tools are generally used for grooving tools and hot forging, hot-working reamers, guillotine, hot-working forging dies, plasticpattern dies, hot-bolt molds, and hot-working tools. Therefore, this study used SKD61 as the material for machining experiments. The increase of hardness of heattreated materials makes machining more difficult, and leads to rapid tool wear.

Table 1. Physical characteristics of die steel SKD61 [47].

\begin{tabular}{cccc}
\hline Physical property & \multicolumn{3}{c}{ Temperature range } \\
\hline Thermal expansion coefficient & $\mathbf{2 0 - 1 0 0 ^ { \circ } \mathrm { C }}$ & $20-250^{\circ} \mathrm{C}$ & $20-500^{\circ} \mathrm{C}$ \\
\cline { 2 - 4 }$\left(\frac{\mathbf{1 0}^{-6}}{\mathbf{K}}\right)$ & 10.5 & 11.3 & 12.1 \\
\hline Thermal conductivity & $20^{\circ} \mathrm{C}$ & $250^{\circ} \mathrm{C}$ & $500^{\circ} \mathrm{C}$ \\
\hline$(\mathrm{W} / \mathrm{mK})$ & 23 & 25 & 27 \\
\hline E-modulus & $21^{\circ} \mathrm{C}$ & $250^{\circ} \mathrm{C}$ & $500^{\circ} \mathrm{C}$ \\
\hline$\left(\frac{\mathrm{KN}^{2}}{\mathrm{~mm}}\right)$ & 210 & 195 & 172 \\
\hline
\end{tabular}

\subsection{Chip color and conformation}

In cutting processes, cutting heat is distributed over three main regions: the chips are discharged from the tool face due to workpiece material exfoliation, shearing, and deformation, and the frictional contact surface between tool flank and workpiece material leads to high temperatures in the workpiece, chips, and cutting tool. If the cutting conditions are appropriate, when the chip thickness decreases, the chips are heated up rapidly under the effect of the cutting heat; this can be determined from the color change or the pyrophoric behavior of the chips. However, the chips are cooled rapidly in air after they are cut off the parent material, and this phenomenon changes the surface color of the chips as a result of the formation of an oxidation film, as shown in Figure 1. The color of this oxidation film is influenced by the oxidation film thickness $(d)$, the refractive index $(n)$, and the absorption coefficients $(k)$ of oxidation film and parent material, as shown in Figure 2. The color of the chips during machining changed in the following order: from light olive gray $(2.5 \mathrm{Y}) \rightarrow$ pale brown $(2.5 \mathrm{Y}) \rightarrow$ weak brown $(5 \mathrm{YR}) \rightarrow$ dusky purple $(10 \mathrm{P}) \rightarrow$ dusky bluish purple (10PB) $\rightarrow$ moderate blue (2.5PB) $\rightarrow$ weak blue $(10 \mathrm{~B}) \rightarrow$ medium bluish-gray $(5 \mathrm{G}) \rightarrow$ light olivegray $(7.5 \mathrm{GY}) \rightarrow$ weak red $(5 \mathrm{R})[48]$.

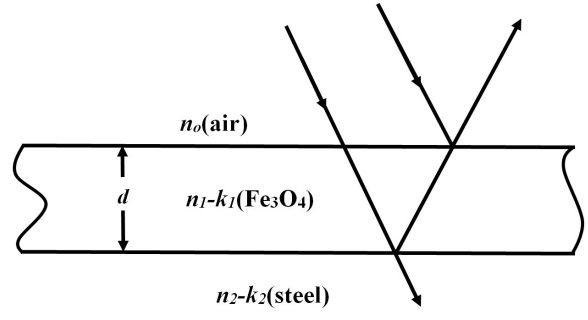

Figure 1. Model of formation of an oxidation film.

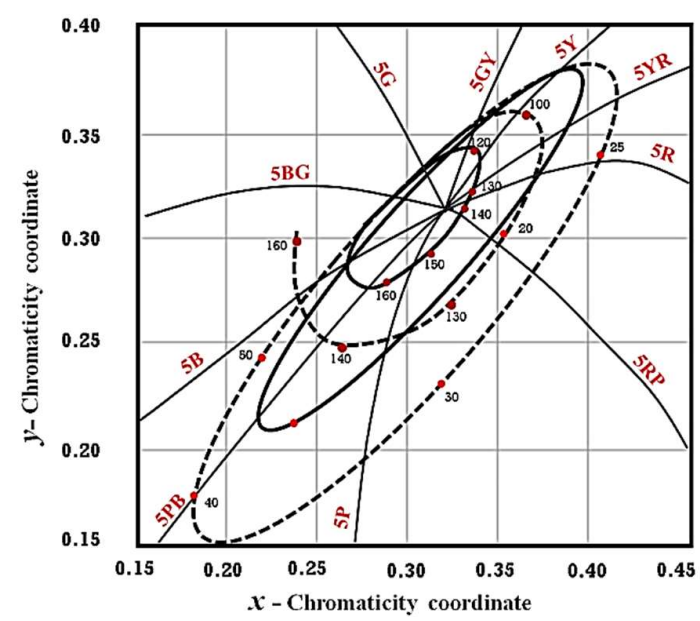

Figure 2. Chromaticity diagram. 
Figure 2 shows the relationship between chip oxidation film thickness and chromaticity coordinate points. The graph displays annular solid lines, which spread radially from the center. $\mathrm{Y}$ indicates yellow, $\mathrm{R}$ red, $\mathrm{P}$ purple, B blue, and G green hues.

\section{Measurement equipment development and modeling}

The cutting tool-wear monitoring system developed in this study was integrated into direct and indirect measurement methods for multi-sensor signal analysis to extract characteristic values and for chip surface chromaticity variation analysis to extract characteristic values, so as to predict the relationship between cutting tool wear values. The proposed system was integrated into a visual man-machine interface including an accelerometer for vibration measurement, a Hall element for voltage measurement, and chip chromaticity coordinate information. The chip chromaticity coordinate values were recorded by a CCD industrial camera, and the extent of damage of the cutting tool was judged according to the chip chromaticity coordinate values. Highly correlated dimensions were selected according to their features. However, direct and indirect methods measure different types of characteristics and use different units of measurement; therefore, a normalization process is required. Finally, the cutting tool wear value was tested and predicted by using BP-LM and GRNN neural network model methods. The experimental process is shown in Figure 3 , including machining parameter setup, sensor signal analysis pre-processing and capture, color reading information and application, and test method of the cutting tool wear model. The stages of the experimental plan and the data collection and analysis process are shown in Figure 4. 


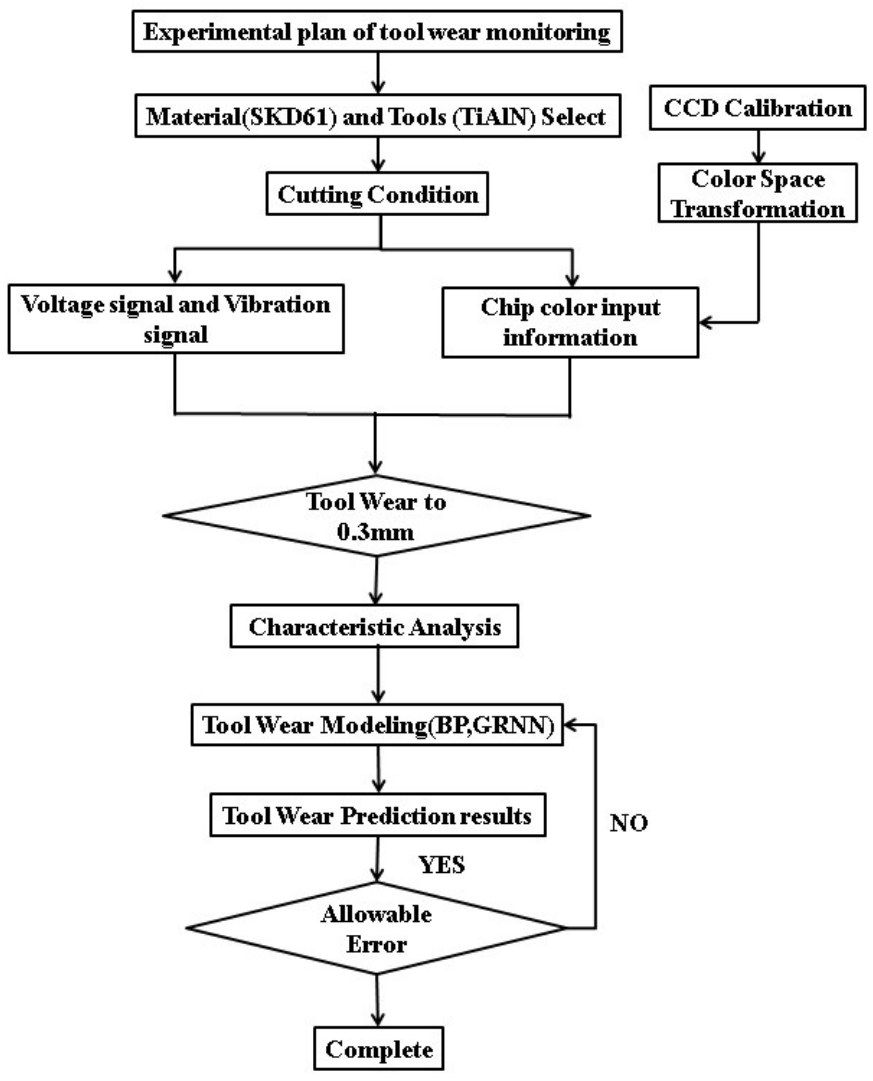

Figure 3. Experimental flow chart.

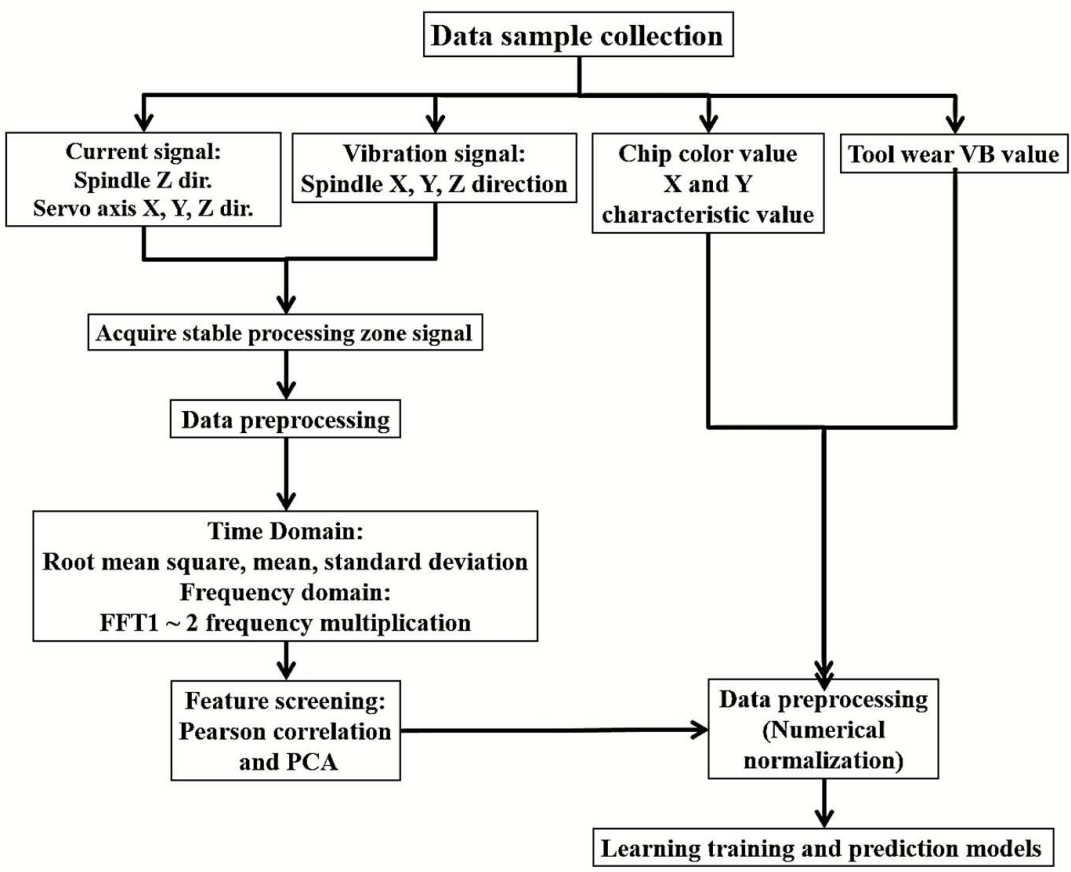

Figure 4. Data collection and analysis process. 


\subsection{Machining experiments}

According to the recommended values of the cutting parameters in the technical information of Mitsubishi tool catalog, for TiAlN-coated carbide blade material, the recommended cutting speed $(\mathrm{m} / \mathrm{min})$ is 50 to $120(\mathrm{~m} / \mathrm{min})$, and the feed per tooth $(\mathrm{mm} / \mathrm{tooth})$ is $\leq 0.2(\mathrm{~mm} / \mathrm{tooth})$. In addition, the recommended depth of cut $(\mathrm{mm})$ is $\leq 0.5(\mathrm{~mm})$. Experimental calculations were performed according to Taylor's formula, and the machining parameter configuration was adjusted, so as to monitor the process from the initial wear to the acute wear of the cutting tool. This study used a machining center for milling. The experimental equipment is shown in Figure 5. Please check if the original meaning is retained on the travel by $450 \mathrm{~mm}, 300 \mathrm{~mm}$, and $360 \mathrm{~mm}$, respectively. The feed velocity was from 36,000 to $48,000 \mathrm{~mm} / \mathrm{min}$, and the maximum revolution of the main spindle was $10,000 \mathrm{rpm}$. The experimental equipment and specifications are described in Table 2 [49].

Table 2. Experimental equipment and specifications

\begin{tabular}{|l|l|}
\hline Items & Experimental design parameters \\
\hline Experiment Material & SKD61 (HRC50) \\
\hline Cutting tool & Milling cutter R5mm \\
\hline Cutting stroke $(\mathrm{mm})$ & 150 \\
\hline Cutting speed(m/min) & 298.3 \\
\hline Cutting feed rate $(\mathrm{mm} / \mathrm{min})$ & 950 \\
\hline Feed per tooth $(\mathrm{mm} /$ tooth $)$ & 0.1 \\
\hline Depth of cut $(\mathrm{mm})$ & 0.5 \\
\hline Cutting width $(\mathrm{mm})$ & 6 \\
\hline Cutting time each time (sec.) & 10 \\
\hline
\end{tabular}

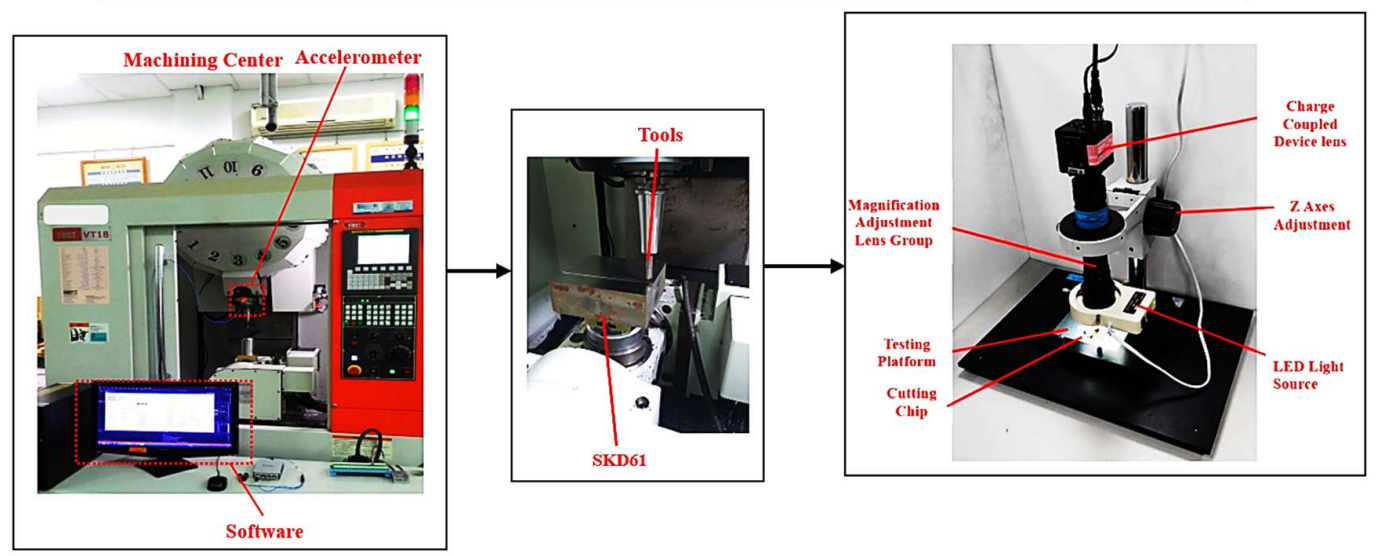

Figure 5. Experimental equipment.

\subsection{Color space transformation process}

The chromatic values, such as R.G.B. values, X.Y.Z. tristimulus values, and $\mathrm{xy}$ chromatic values, of chip color and equipment data were transformed. In terms of the display, the proposed system receives electronic signals, mixes the colors according to their signal intensity, determines the corresponding colors, and displays them on the screen. Therefore, the color on the display is transformed in a different way compared to the mathematical computation model of colorimetry. The process of color space transformation is detailed below. The process of color space transformation operated by the display system is shown in Figure 6 [50-52]. 


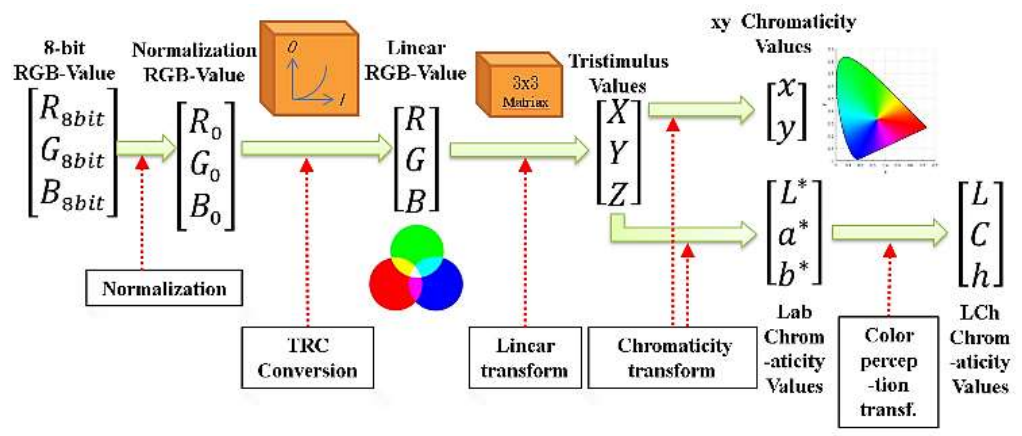

Figure 6. Color space transformation process.

The main process for the creation of chip color and measurement equipment data is described below.

\section{Step-1. Normalization}

The initial input of color signals in the display are (R8-bit G8-bit B8-bit) 8-bit R.G.B. signal values, and the numerical range of the three primary colors is $0-255$, transformed to $\left[R_{0} G_{0} B_{0}\right]$ normalized R.G.B. signal values:

$$
I_{0}=\frac{I}{255}
$$

where $I_{0}=R_{0}, G_{0}, B_{0}$ is the normalized R.G.B. signal value, and $I=R_{8-b i t}, G_{8-b i t}, B_{8-b i t}$ is the 8-bit R.G.B. signal value

\section{Step-2. TRC Transformation}

TRC is the abbreviation for Tone Reproduction Curve, representing the relationship between display input signal value and brightness. The normalized RGB values ( $R_{0} G_{0} B_{0}$ ) are transformed by TRC into linear RGB values ( $R G B$ ). In a general way, the display uses a $\gamma$ value to represent the tone relationship between the normalized RGB values and the linear R.G.B. values. The $\gamma$ value varies with the display specifications, generally between 1.8 and 2.4:

$$
\begin{aligned}
& \mathrm{R}=\left(R_{0}\right)^{\gamma_{R}} . \\
& \mathrm{G}=\left(G_{0}\right)^{\gamma_{G}} . \\
& \mathrm{B}=\left(B_{0}\right)^{\gamma_{B} .} .
\end{aligned}
$$

where R, G, and B are linear RGB signal values, and $\gamma_{R}, \gamma_{G}, \gamma_{B}$ are the $\gamma$ values corresponding to $\mathrm{R}, \mathrm{G}$, and $\mathrm{B}$.

\section{Step-3. Linear Transformation}

Linear transformation transforms linear RGB values [R G B] to XYZ tristimulus values [X Y Z]; a $3 \times 3$ matrix is calculated in the process. The $3 \times 3$ transformation matrix varies with the display of different standards; the standards for different kinds of displays will be detailed in Section 3.2:

$$
\begin{gathered}
{\left[\begin{array}{l}
X \\
Y \\
Z
\end{array}\right]=\left[\begin{array}{lll}
2.7689 & 1.7517 & 1.1302 \\
1.0000 & 4.5907 & 0.0601 \\
0.0000 & 0.0565 & 5.5943
\end{array}\right]\left[\begin{array}{l}
\mathrm{R} \\
\mathrm{G} \\
\mathrm{B}
\end{array}\right] .} \\
{\left[\begin{array}{l}
X \\
Y \\
Z
\end{array}\right]=M\left[\begin{array}{l}
\mathrm{R} \\
\mathrm{G} \\
\mathrm{B}
\end{array}\right] .}
\end{gathered}
$$

where $\mathrm{X}, \mathrm{Y}$, and $\mathrm{Z}$ are tristimulus values, and $\mathrm{M}$ is the $3 \times 3$ linear transformation matrix 


\section{Step-4. Chromaticity transformation}

The tristimulus values $\left[X Y Z\right.$ ] can be transformed to $[x y Y]$ and $\left[\mathrm{L}^{*} \mathrm{a}^{*} \mathrm{~b}^{*}\right]$, according to the International Commission on Illumination (CIE) $x$ y chromaticity diagram, known as CIE $1976 \mathrm{~L}^{*} \mathrm{a}^{*} \mathrm{~b}^{*}$, which provides a three-dimensional representation for the perception of color stimuli by a standard observer under strictly standardized light sources, as shown in Figure 4.

The formulas to transform tristimulus values to chromaticity values are the following:

$$
\begin{aligned}
& L^{*}=116\left(\frac{y}{y_{n}}\right)-16 \\
& a^{*}=500\left(f\left(\frac{x}{x_{n}}\right)-f\left(\frac{y}{y_{n}}\right)\right) \\
& b^{*}=500\left(f\left(\frac{y}{y_{n}}\right)-f\left(\frac{z}{z_{n}}\right)\right) \\
& f\left(\frac{I}{I_{n}}\right)=7.787\left(\frac{I}{I_{n}}\right)+\frac{16}{116}, \text { if }\left(\frac{I}{I_{n}}\right) \leq 0.008856 .
\end{aligned}
$$

where I / In $=X / X_{n}=Y / Y_{n}=Z / Z n ; X, Y$, and $Z$ are tristimulus values of an object, and $X_{n}, Y_{n}$, and $Z_{n}$ are tristimulus values of the reference white. $Z$ he tristimulus values vary with different kinds of light sources, as shown in Figure 7 [53].

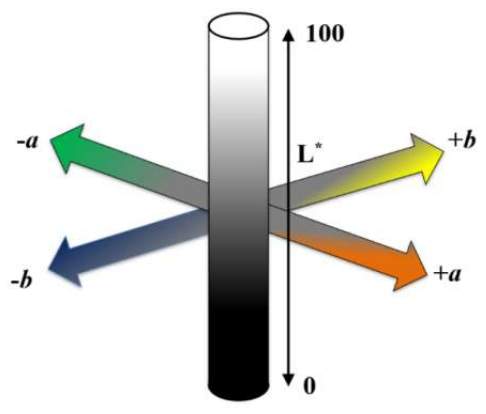

Figure 7. Three-dimensional CIELAB color space where the $L^{*}$ axis represents the color's lightness.

\section{Step-5. Color Perception Transformation}

This step transforms $\left[L^{*} a^{*} b^{*}\right]$ of the CIE LAB color space into a color perception attribute value of $\left[\mathrm{L} \mathrm{C} \mathrm{h]}\right.$. L, $C_{a b^{*}}$, and $h_{a b}$ represent lightness, chroma, and hue, respectively:

$$
\begin{gathered}
C_{a b^{*}}=\sqrt{\left[\left(\mathrm{a}^{*}\right)^{2}+\left(\mathrm{b}^{*}\right)^{2}\right]} . \\
h_{a b}=\tan ^{-1}\left(\frac{\mathrm{b}^{*}}{\mathrm{a}^{*}}\right) .
\end{gathered}
$$

where the $h_{a b}$ computing $a^{*}$ and $b^{*}$ will have different combinations of positive values or negative values, the absolute value of $\left(\frac{b^{*}}{a^{*}}\right)$ is taken, and then the appropriate angle is worked out according to its coordinates in the quadrant, to finally obtain the $\mathrm{x}$ and $\mathrm{y}$ chromaticity values. 


\subsection{Color information reading and calibration}

Eq.11, 12, 13 transform $\mathrm{R}^{\prime} \mathrm{G}^{\prime} \mathrm{B}^{\prime}$ obtaining the regression equation of color space CIE LAB and then the matrix of eq. 16 ; the $\mathrm{R}^{\prime} \mathrm{G}^{\prime} \mathrm{B}^{\prime}$ values and the CIE LAB standard values attached to the Color Checker Passport color chart are substituted in Eq. 4 to calculate the values of the color correction matrix $\mathrm{M}$; therefore, the color correction model is obtained. If the color correction capability is insufficient, the shooting environment is improved till the chromatic aberration grade reaches the target level. Finally, the material chips are shot to obtain the parameters for judging the cutting tool wear. The color correction process of the image capture equipment is shown in Figure 8 [51].

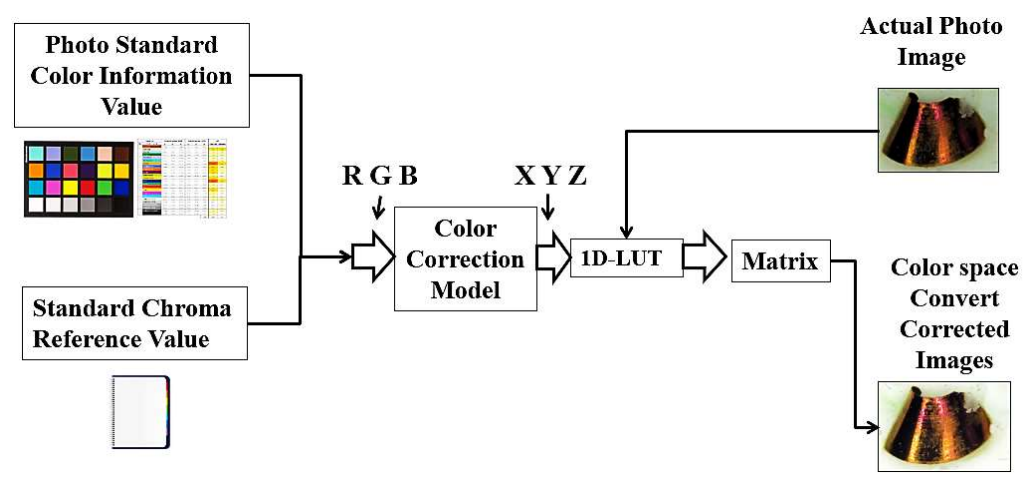

Figure 8. Color correction process of the image capture equipment.

$$
\begin{aligned}
& \mathrm{L}^{*}=\mathrm{a}_{0}+\mathrm{a}_{1} \mathrm{R}^{\prime}+\mathrm{a}_{2} \mathrm{G}^{\prime}+\mathrm{a}_{3} \mathrm{~B}^{\prime}+\mathrm{a}_{4} \mathrm{R}^{\prime} \mathrm{G}^{\prime}+\mathrm{a}_{5} \mathrm{R}^{\prime} \mathrm{B}^{\prime}+\mathrm{a}_{6} \mathrm{G}^{\prime} \mathrm{B}^{\prime} \\
& +a_{7} R^{\prime 2}+a_{8}{G^{\prime 2}}^{2}+a_{9} B^{\prime 2}+a_{10} R^{\prime} G^{\prime} B^{\prime}+a_{11} R^{\prime 3} \\
& +\mathrm{a}_{12} \mathrm{G}^{3}+\mathrm{a}_{13} \mathrm{~B}^{\prime 3} \text {. } \\
& \mathrm{a}^{*}=\mathrm{b}_{0}+\mathrm{b}_{1} \mathrm{R}^{\prime}+\mathrm{b}_{2} \mathrm{G}^{\prime}+\mathrm{b}_{3} \mathrm{~B}^{\prime}+\mathrm{b}_{4} \mathrm{R}^{\prime} \mathrm{G}^{\prime}+\mathrm{b}_{5} \mathrm{R}^{\prime} \mathrm{B}^{\prime}+\mathrm{b}_{6} \mathrm{G}^{\prime} \mathrm{B}^{\prime} \\
& +b_{7} R^{\prime 2}+b_{8} G^{\prime 2}+b_{9} B^{\prime 2}+b_{10} R^{\prime} G^{\prime} B^{\prime}+b_{11} R^{\prime 3} \\
& +b_{12} G^{\prime 3}+b_{13} B^{\prime 3} \text {. } \\
& \mathrm{b}^{*}=\mathrm{c}_{0}+\mathrm{c}_{1} \mathrm{R}^{\prime}+\mathrm{c}_{2} \mathrm{G}^{\prime}+\mathrm{c}_{3} \mathrm{~B}^{\prime}+\mathrm{c}_{4} \mathrm{R}^{\prime} \mathrm{G}^{\prime}+\mathrm{c}_{5} \mathrm{R}^{\prime} \mathrm{B}^{\prime}+\mathrm{c}_{6} \mathrm{G}^{\prime} \mathrm{B}^{\prime}+\mathrm{c}_{7} \mathrm{R}^{\prime 2} \\
& +\mathrm{c}_{8} \mathrm{G}^{\prime 2}+\mathrm{c}_{9} \mathrm{~B}^{\prime 2}+\mathrm{c}_{10} \mathrm{R}^{\prime} \mathrm{G}^{\prime} \mathrm{B}^{\prime}+\mathrm{c}_{11} \mathrm{R}^{\prime 3}+\mathrm{c}_{12} \mathrm{G}^{\prime 3} \\
& +\mathrm{c}_{13} \mathrm{~B}^{\prime 3} \text {. } \\
& =\left[\begin{array}{lllllllllll}
1 & \mathrm{R}^{\prime} & \mathrm{G}^{\prime} & \mathrm{B}^{\prime} & \mathrm{R}^{\prime} \mathrm{G}^{\prime} & \mathrm{R}^{\prime} \mathrm{B}^{\prime} & \mathrm{G}^{\prime} \mathrm{B}^{\prime} & \mathrm{R}^{\prime 2} & \mathrm{G}^{\prime 2} & \mathrm{~B}^{\prime 2} & \mathrm{R}^{\prime} \mathrm{G}^{\prime} \mathrm{B}^{\prime}
\end{array}\right. \\
& \times\left[\begin{array}{ccc}
\mathrm{a}_{0} & \mathrm{~b}_{0} & \mathrm{c}_{0} \\
\mathrm{a}_{1} & \mathrm{~b}_{1} & \mathrm{c}_{1} \\
\vdots & \vdots & \vdots \\
\mathrm{a}_{13} & \mathrm{~b}_{13} & \mathrm{c}_{13}
\end{array}\right]
\end{aligned}
$$

\section{Results and Discussion}

\subsection{Wear analysis result sof TiAlN-coated tips}

This study used three machining experiments to repeat the test. Each group of TiAlN-coated tips was cut 10 times, as shown in Figures 9 and 10. The correlation of the number of cuttings to the chip morphology and the degree of cutting tool wear is discussed. At the 11th cutting, the degree of wear was acute, and the left front end of the chips appeared curled. However, when observing the gloss of the chip surface color from the $2^{\text {nd }}$ to the $7^{\text {th }}$ cutting, the cutting tool wear was stable, and the chip 
surface color was purple-blue. After the $7^{\text {th }}$ cutting, the degree of the cutting tool wear increased and then at the 8th cutting, the chip surface color turned from purple-blue to dark purple-blue and dark blue. Finally, at the 11th cutting, the degree of wear became acute, and the chip surface color turned from dark blue to cyan.

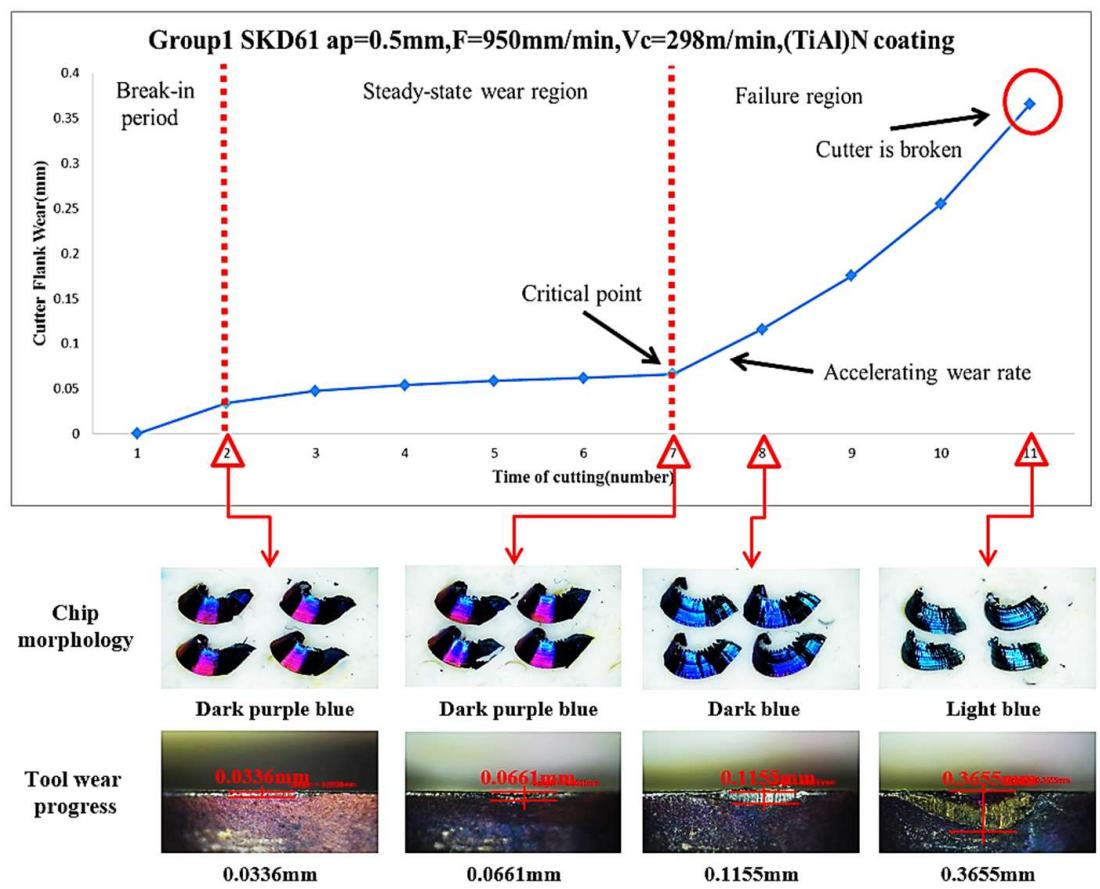

Figure 9. Degree of cutting tool wear and chip morphology of TiAlN-coated tips (Group 1 of experiments on dry cutting).

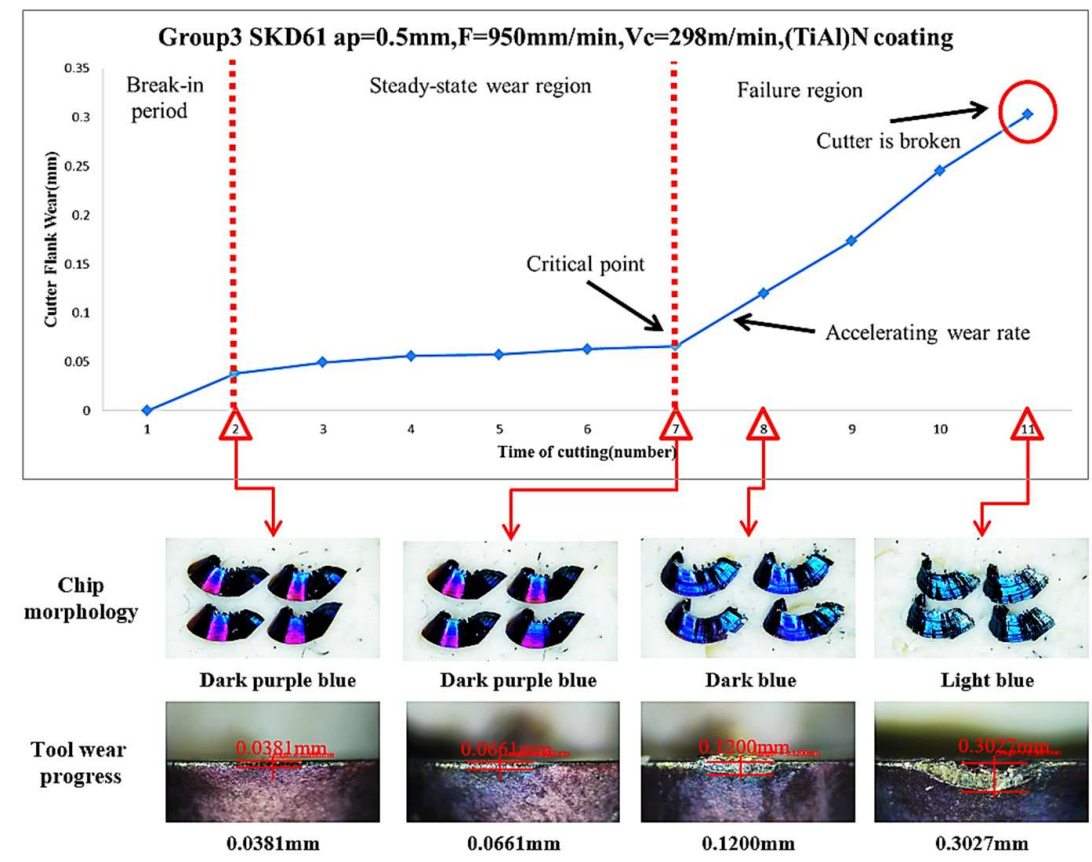

Figure 10. Degree of cutting tool wear and chip morphology of TiAlN-coated tips (Group 3 of experiments on dry cutting). 


\subsection{Test and validation of the cutting tool wear prediction model}

The correlation between carbide blade wear and chip surface chromaticity eigenvalue for three groups of TiAlN-coated tips was determined. Three phenomena can be observed in Figures 11 and 12. First, cuttings No. 2, 7, 8, and 11 were selected to observe the change in chip surface chromaticity. We observed that, as the cutting tool wear increased, the $X$ and $Y$ characteristic values of chip surface chromaticity shifted clockwise. Secondly, when the cutting tool turned from the initial unworn state to the acute wear state, the chip surface chromaticity eigenvalue varied in the following way: purple $\rightarrow$ purple blue $\rightarrow$ blue $\rightarrow$ cyan. Thirdly, at the 7 th and 8 th cuttings, aliasing of chip chromaticity $X$ characteristic value and $Y$ characteristic value occurred, and the cutting tool wear accelerated, reaching the unstable state region, as shown in Figure 13.

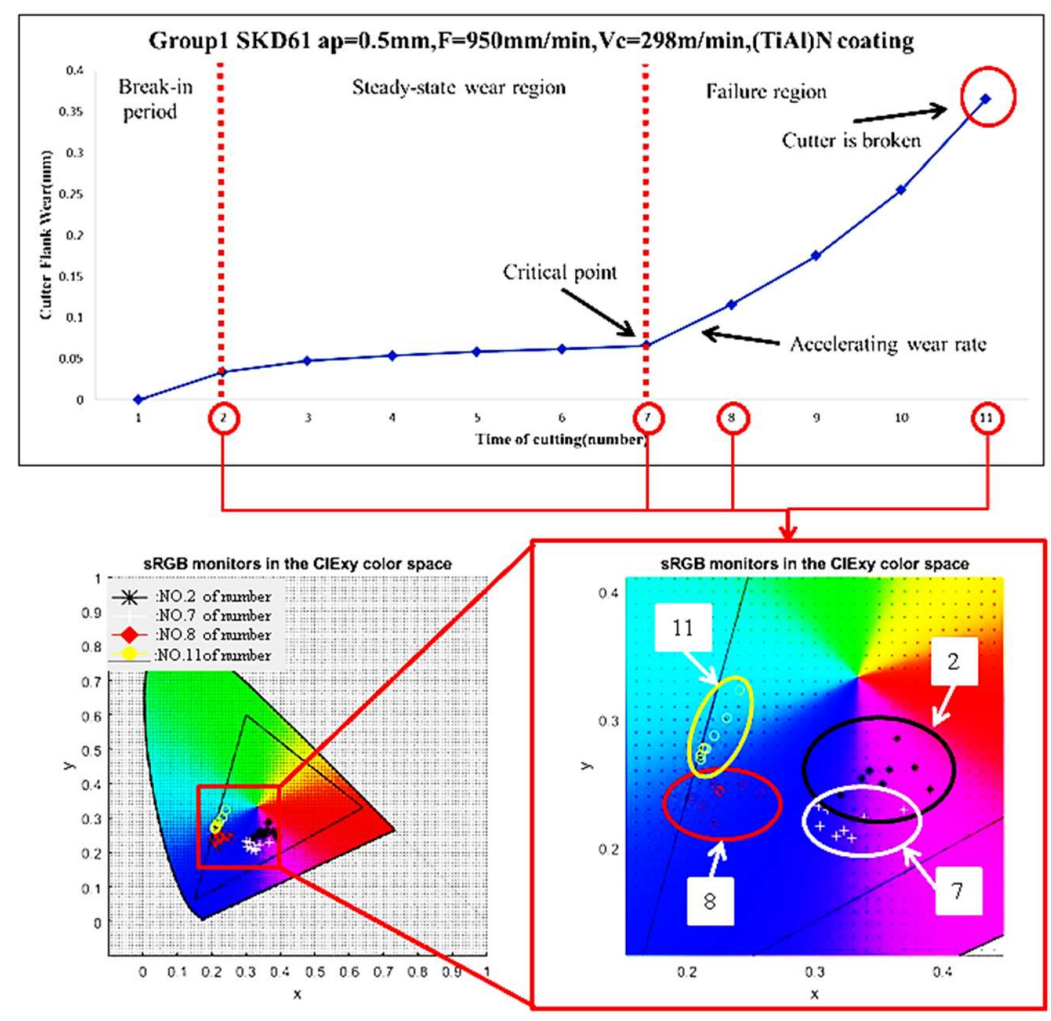

Figure 11. Degree of cutting tool wear and chromaticity coordinate points of TiAlN-coated tips (Group 1 of experiments on dry cutting). 


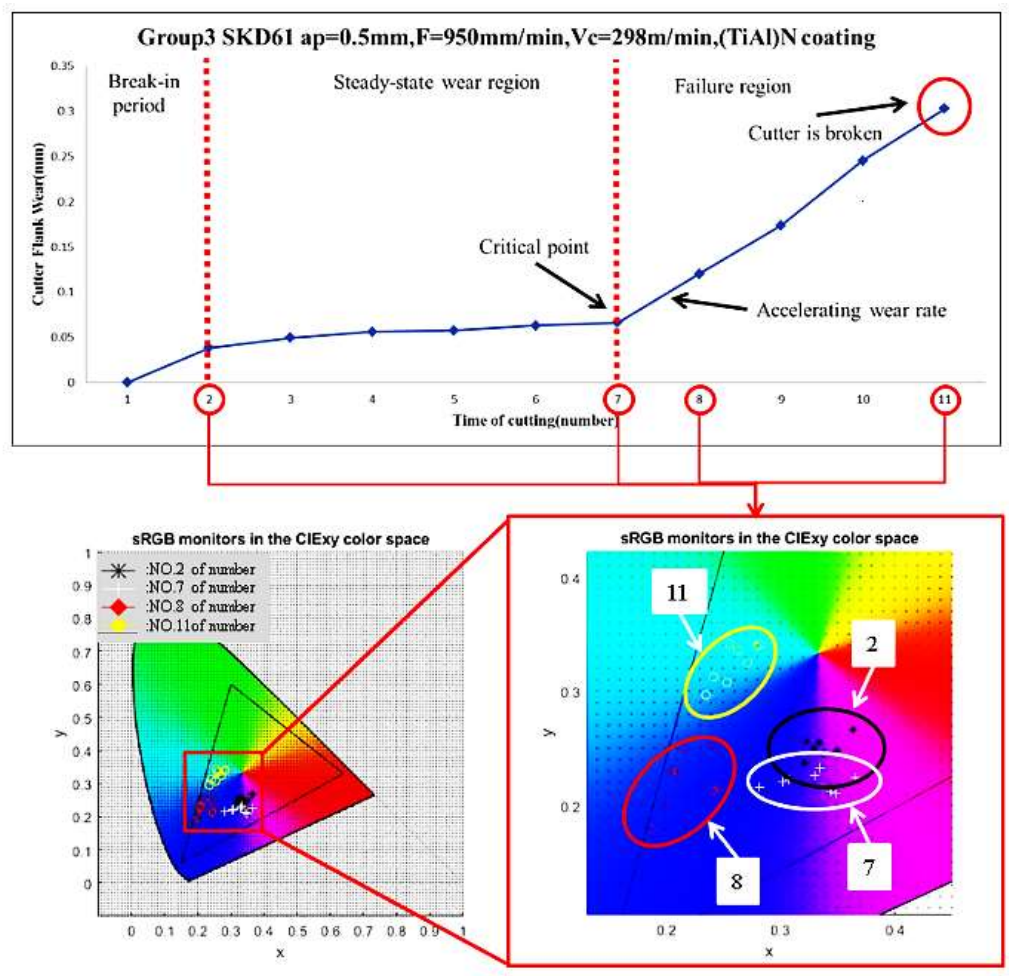

Figure 12. Degree of cutting tool wear and chromaticity coordinate points of TiAlN-coated tips (Group 3 of experiments on dry cutting).

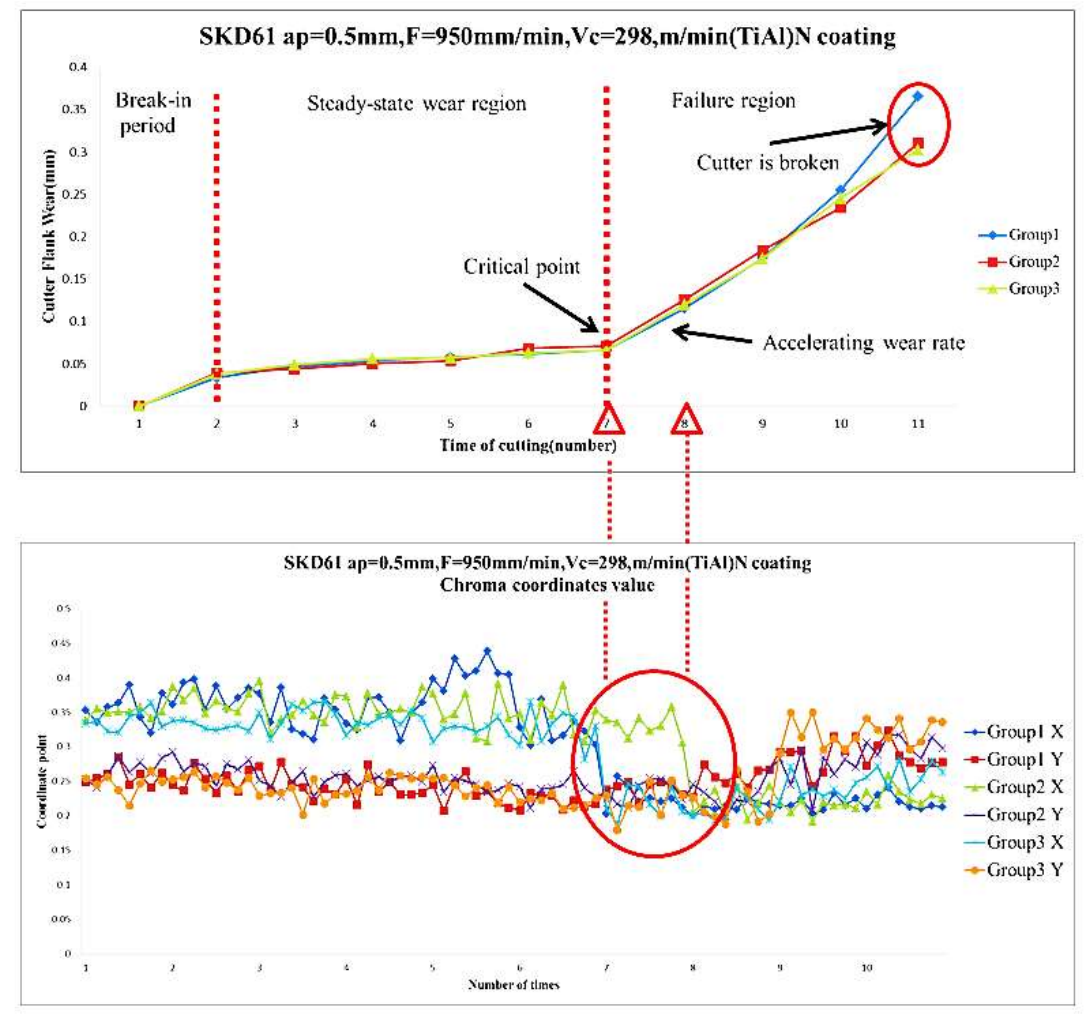

Figure 13. Degree of cutting tool wear and chromaticity coordinate characteristic values of TiAlN-coated tips in three groups of experiments on dry cutting. 


\subsection{Test error analysis results of the TiAlN cutting tool wear prediction model}

We performed three sets of repeated cutting tests. Each group consisted of 10 cuttings. Each characteristic value had 80 data points; 50 values were used for training, and 30 values were used for the test, to confirm the accuracy of the cutting tool wear prediction model built in this study. The analysis results of the BP-LM and GRNN neural network models were divided into three phases to determine the MAPE of the model prediction with respect to the actual cutting tool wear loss. In phase 1, the measured voltage signal characteristic was used as the input layer of the neural network. In phase 2 , the measured vibration signal characteristic was used as the input layer of the neural network. In phase 3, the characteristic values of voltage and vibration signals were combined with the chip surface chromaticity eigenvalue as the input layer of the neural network. The errors for the predicted values of six groups of machining experiments with respect to the actual cutting tool wear values are discussed below and shown in Figures 14 and 15. This study used the BP-LM neural network model to predict the cutting tool wear value. Phase 1 used the voltage signal characteristic value as the input layer; the predicted cutting tool wear value is shown in Tables 3 and 4, and the percentage errors of MAPE were $10.87 \%, 6.6 \%$, and $19.37 \%$. Therefore, we observed that when the voltage signal characteristic value is used as an input feature, the tool wear trend can be estimated, but there are still obvious errors. Phase 2 used the vibration signal characteristic value as the input layer; the predicted cutting tool wear value showed that the MAPE were $9.44 \%, 14.82 \%$, and $9.89 \%$. This shows that the vibration signal characteristic value for predicting cutting tool wear provided a better result than the voltage signal characteristic value. Phase 3 used the vibration signal, voltage signal, and chip surface chromaticity combined for a multi-sensor prediction of the cutting tool wear. The predicted cutting tool wear shows that MAPE were $8.69 \%, 7.52 \%$, and $7.34 \%$. Therefore, when the characteristic value of chip surface chromaticity was included, the cutting tool wear could be predicted more accurately than when using a single sensor signal characteristic value.

Group1 BP-LM Method Prediction Error ap $=0.5 \mathrm{~mm}, \mathrm{~F}=950 \mathrm{~mm} / \mathrm{min}, \mathrm{Vc}=298 \mathrm{~m} / \mathrm{min}, \mathrm{TiAIN}$ coating

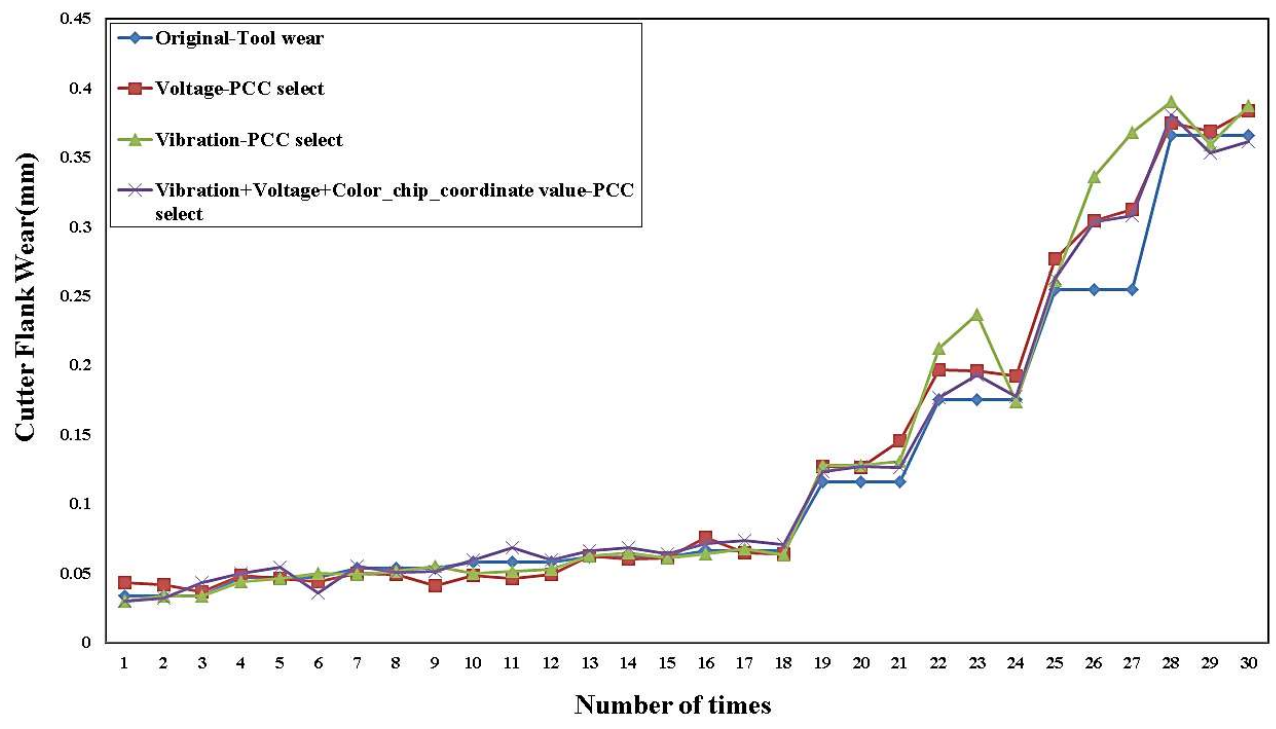

Figure 14. Group 1 cutting tool wear prediction result for TiAlN-coated tips using the BP-LM prediction model. 
Table 3. Group 1 cutting tool wear prediction error percentage of TiAlN-coated tips using the BP-LM prediction model.

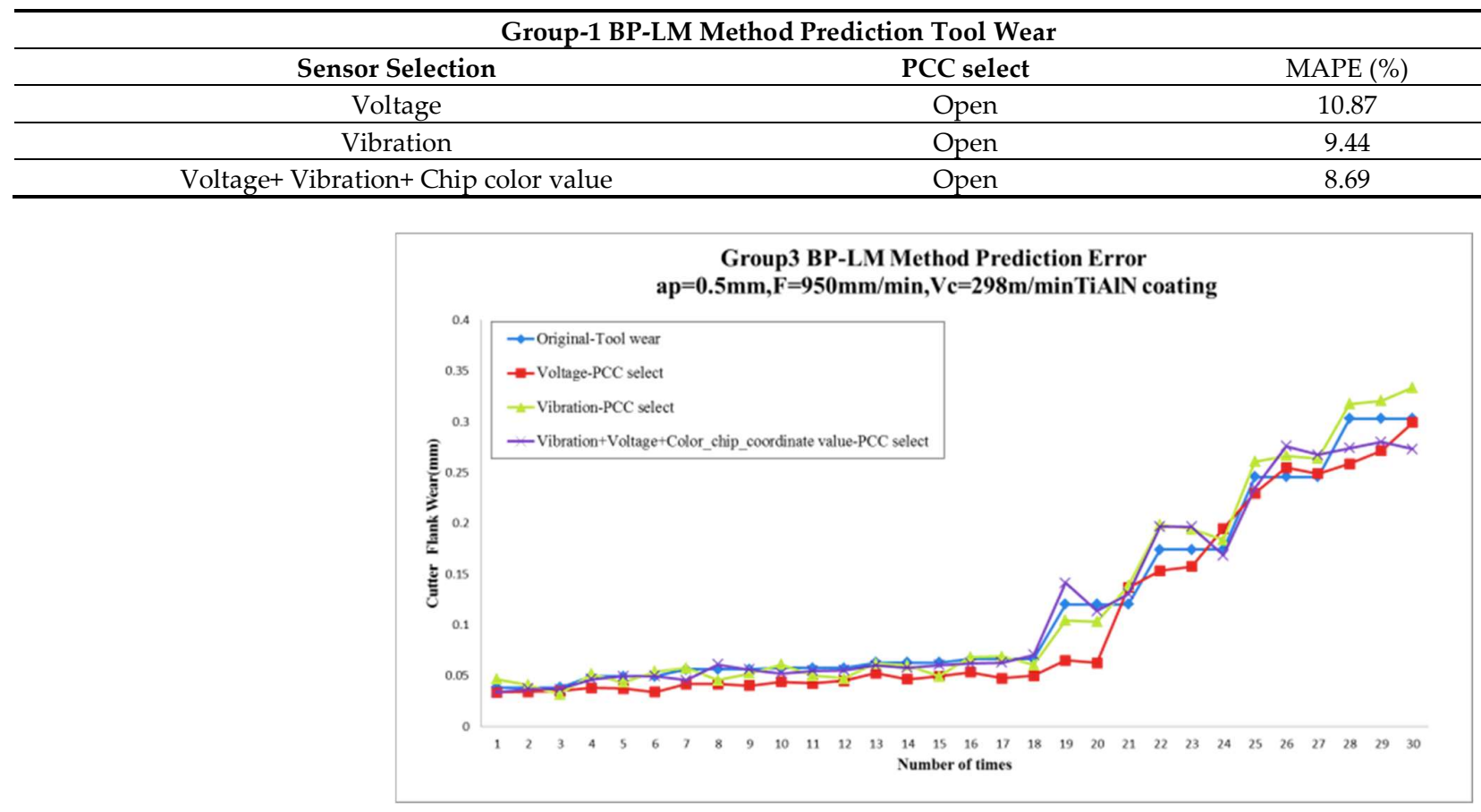

Figure 15. Group 3 cutting tool wear prediction result for TiAlN-coated tips using the BP-LM prediction model.

Table 4. Group 3 cutting tool wear prediction error percentage of TiAlN-coated tips using the in BP-LM prediction model.

\begin{tabular}{ccc}
\hline \multicolumn{3}{c}{ Group-3 BP-LM Method Prediction Tool Wear } \\
\hline Sensor Selection & PCC select & MAPE (\%) \\
\hline Voltage & Open & 19.37 \\
\hline Vibration & Open & 9.89 \\
\hline Voltage+ Vibration+ Chip color value & Open & 7.34 \\
\hline
\end{tabular}

Afterward, this study used the GRNN neural network model to predict the cutting tool wear value, as shown in Figures 16 and 17. The first phase used the voltage signal characteristic value as the input layer; the predicted cutting tool wear value is shown in Tables 5 and 6, and the MAPE were $10.35 \%, 8.95 \%$, and $12.93 \%$. Therefore, we observed that, when the voltage signal characteristic value was used as an input feature, the tool wear trend could be estimated, but obvious errors remained. Phase 2 used the vibration signal characteristic value as the input layer; the predicted cutting tool wear showed that MAPE were $8.59 \%$, 8.04\%, and 7.27\%. According to the prediction result, the vibration signal characteristic value provided a better prediction of the cutting tool wear than the voltage signal characteristic value. Phase 3 combined the vibration signal, voltage signal, and chip surface chromaticity for a multisensor prediction of the cutting tool wear. The predicted cutting tool wear value showed that the MAPE were 7.38\%,7.3\%, and 5.09\%. Therefore, adding the characteristic value of chip surface chromaticity allowed a more accurate prediction of the cutting tool wear than when using a single sensor signal characteristic value. 
Group1 GRNN Method Prediction Error ap $=0.5 \mathrm{~mm}, \mathrm{~F}=950 \mathrm{~mm} / \mathrm{min}, \mathrm{Vc}=298 \mathrm{~m} / \mathrm{min}, \mathrm{TiAlN}$ coating

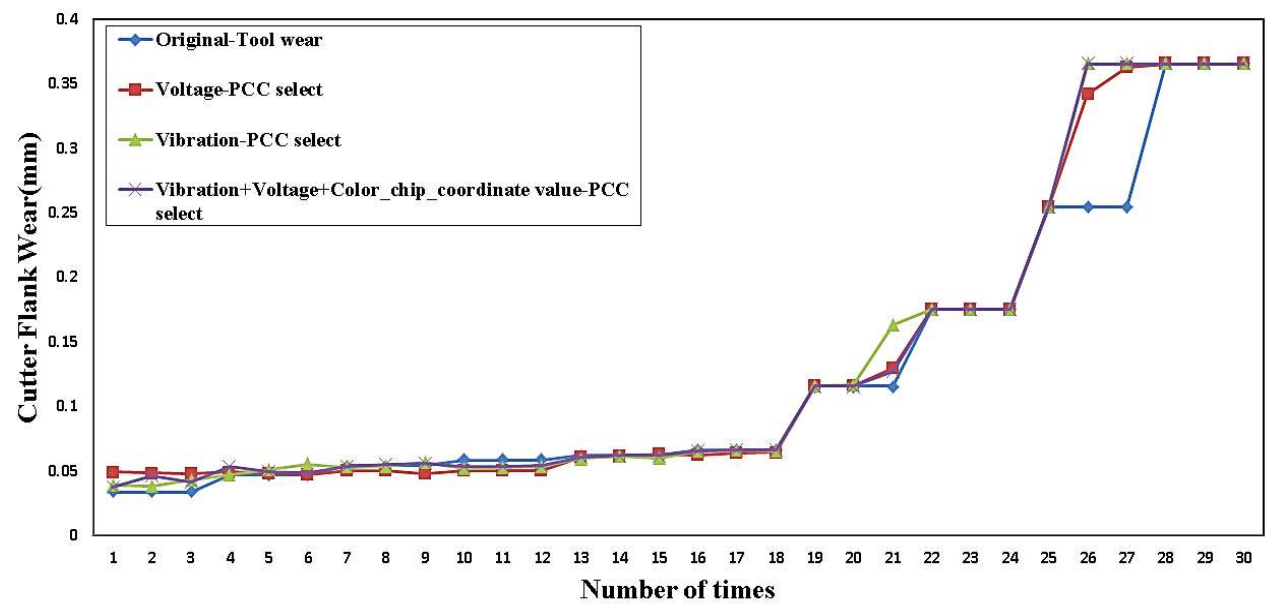

Figure 16. Group 1 cutting tool wear prediction result for TiAlN-coated tips using the GRNN prediction model.

Table 5. Group 1 cutting tool wear prediction error percentage for TiAlN-coated tips using the GRNN prediction model.

\begin{tabular}{ccc}
\hline \multicolumn{3}{c}{ Group-1 GRNN Method Prediction Tool Wear } \\
\hline Sensor Selection & PCC select & MAPE (\%) \\
\hline Voltage & Open & 10.35 \\
\hline Vibration & Open & 8.59 \\
\hline Voltage+ Vibration+ Chip color value & Open & 7.38 \\
\hline
\end{tabular}

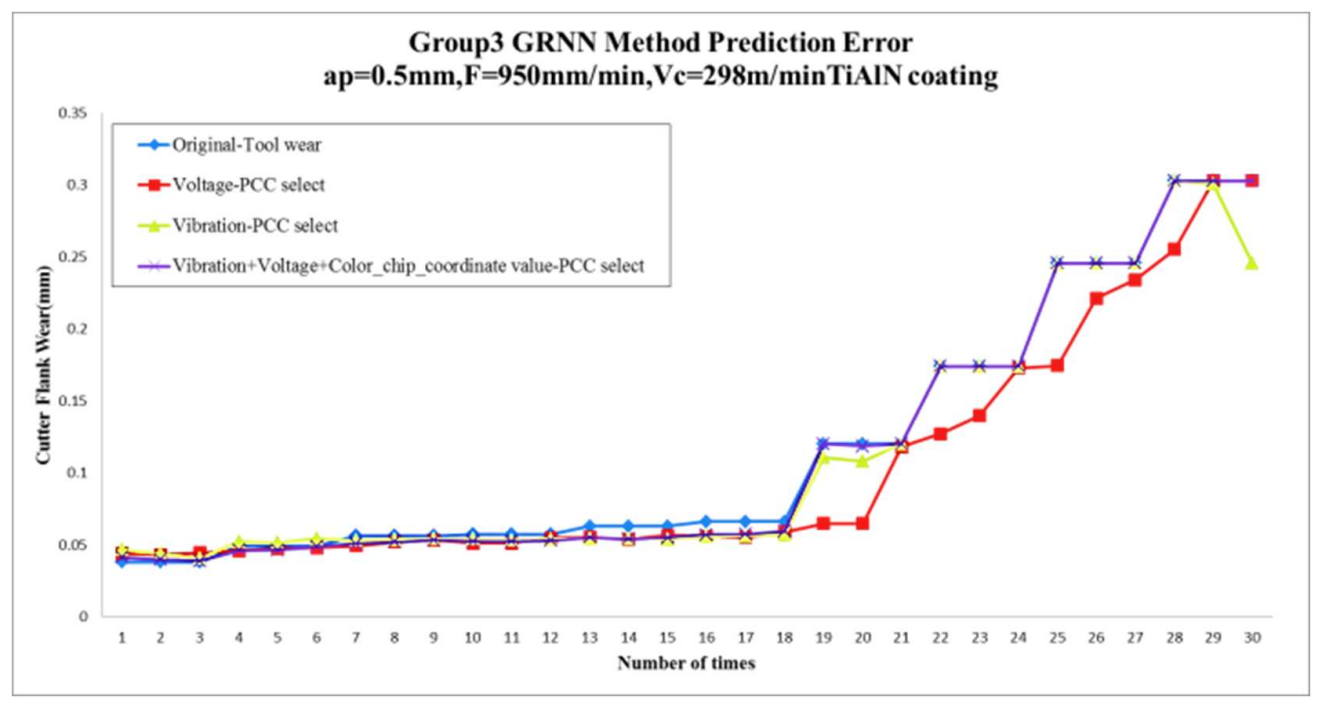

Figure 17. Group 3 cutting tool wear prediction result for TiAlN-coated tips using the GRNN prediction model. 
Table 6. Group 3 cutting tool wear prediction error percentage for TiAlN-coated tips using the GRNN prediction model.

\begin{tabular}{ccc}
\hline \multicolumn{3}{c}{ Group-3 GRNN Method Prediction Tool Wear } \\
\hline Sensor Selection & PCC select & MAPE (\%) \\
\hline Voltage & Open & 12.93 \\
\hline Vibration & Open & 7.27 \\
\hline Voltage+ Vibration+ Chip color value & Open & 5.09 \\
\hline
\end{tabular}

The results for three cutting samples were analyzed by using the BP-LM and GRNN neural network models. The results obtained by using the combined vibration signal, voltage signal, and chip surface chromaticity and the related MAPE values were evaluated, and the between model predicted values and actual cutting tool wear loss were compared, as shown in Table 7. The average value of the prediction error for the BP-LM method was 7.85\%, and the average value of the prediction error for the GRNN method was $6.59 \%$. Therefore, the error range of MAPE is $<10 \%$ for the BP-LM and GRNN prediction methods, indicating a high predicting ability.

Table 7. Cutting tool wear prediction percentage errors of BP-LM and GRNN methods for three cutting groups of TiAlN-coated tips.

\begin{tabular}{ccc}
\hline \multicolumn{3}{c}{ TiAlN-Tool Wear Prediction Error } \\
\hline Number of Cutting Groups & BP-LM method MAPE (\%) & GRNN method MAPE (\%) \\
\hline Group-1 & 8.69 & 7.38 \\
\hline Group-2 & 7.52 & 7.3 \\
\hline Group-3 & 7.34 & 5.09 \\
\hline Average & 7.85 & 6.59 \\
\hline
\end{tabular}

\section{Conclusion}

This system allows a simple and rapid measurement of cutting tool wear, based on chips imaging and cutting time recording, which can be useful in industrial applications. This proposed process includes CCD calibration, tool wear repeatability, chip color determination, and tool wear prediction. The following conclusions are derived from the described experiments.

1. In terms of equipment calibration, without color correction, as this system is free of standards, it cannot be shared with other imaging systems or evaluate color reproducibility. The color correction model of this study can reduce the color difference from $\Delta \mathrm{E}_{\mathrm{ab}}^{*}=18.6$ to 2.94 , and the rate of improvement is $84.19 \%$.

2. The analysis of the relationship between tool wear and chip color established a correlation between TiAlN-coated carbide blade wear and chip surface chromaticity eigenvalue; as the cutting tool wear increases, chip surface color varies in the following way: purple $\rightarrow$ purple blue $\rightarrow$ blue $\rightarrow$ cyan, including also green and yellow; when the cutting tool is in the accelerating wear phase, the trend of color change is especially obvious.

3. When using the BP methodology for wear prediction, using voltage, vibration signal, and chip color, the Mean Absolute Percentage Error (MAPE) for the voltage signal was $12.28 \%$, for the vibration signal it was $11.38 \%$, and for the chip color combined with multi-sensor signal characteristics it was $7.85 \%$. The MAPE value for the chip color was the smallest. When using the GRNN methodology the MAPE for the voltage signal was $10.74 \%$, for the vibration signal it was $7.96 \%$, and for the chip color combined with multi-sensor characteristics it was $6.59 \%$. Therefore, the superiority of the chip color combined with multi-sensor characteristics is obvious. 
4. The data analysis showed that the average MAPE of the predicted value of TiAlN-coated cutting tool wear was $10 \%$ when single vibration and voltage eigenvalues were used as input features. When the voltage signal characteristic value, vibration signal characteristic value, and chip surface chromaticity characteristic value were combined, the average prediction error of the BP-LM method was $7.85 \%$, and the average prediction error of the GRNN method was $6.59 \%$. Therefore, when the characteristic value of chip surface chromaticity was included for wear prediction, the prediction accuracy was enhanced compared to predictions obtained by using single values.

5. Future research lines will be using different cutting conditions and applications. Three topics will be followed: first to observe the relationship between chip geometry and weight on-chip color, the Convolutional Neural Networks (CNN) method will be used for analysis and prediction.; second, develop and design tool holders for real-time measurement of cutting temperature.; Three, in wet cutting, the Minimum Quantity Lubrication (MQL) method will be used for experimentation and analysis of chip color, at this time, as the topics also form part of an ongoing study.

\section{Nomenclature:}

$\mathrm{I}_{0}=\mathrm{R}_{0} 、 \mathrm{G}_{0} 、 \mathrm{~B}_{0}$ normalized RGB signal values.

$\mathrm{I}=$ R8-bit 、 G8-bit、B8-bit new 8-bit RGB signal values.

$\gamma_{R}, \gamma_{G}, \gamma_{B}=$ correspond to the $\gamma$ value of RGB.

$\mathrm{X}, \mathrm{Y}, \mathrm{Z}=$ tristimulus values.

$\mathrm{X}_{\mathrm{n}}, \mathrm{Y}_{\mathrm{n}}, \mathrm{Z}_{\mathrm{n}}=$ benchmark-white tristimulus value.

$\mathrm{L}=$ brightness.

$C_{a b^{*}}=$ chroma and hue.

$h_{a b}=$ respectively.

$\mathrm{Vc}=$ cutting velocity $(\mathrm{m} / \mathrm{min})$.

$\mathrm{T}=$ Tool Life (min).

$\mathrm{fz}=$ feed per tooth ( $\mathrm{mm} /$ tooth).

tc $=$ means chip thickness $(\mathrm{mm})$.

$r_{\varepsilon}=$ nose radius (mm).

$\mathrm{a}_{\mathrm{p}}=$ cutting depth $(\mathrm{mm})$.

\section{Reference:}

1. Quadro, A. L.; Branco, J. R. T. Analysis of the acoustic emission during drilling test. Surface and Coating Technology. 1997, 94$95,1-3,691-695$.

2. Ravindra, H. V.; Srinivasa, Y. G.; Krishnamurthy, R. Acoustic emission for tool condition monitoring in metal cutting. Wear. 1997, 212, 78-84.

3. I. Abu-Mahfouz. Drilling wear detection and classification using vibration signals and artificial neural network. Int. J. Mach. Tools Manuf. 2003, 43, 707-720.

4. Choi, Y.J.; Park, M. S.; Chu, C. N. Prediction of drill failure using features extraction in time and frequency domains of feed motor current. Int. J. Mach. Tools Manuf. 2008, 48, 29-39.

5. Oh, Y. T.; Kwon, W.T.; Chu, C.N. Drilling torque control using spindle motor current and its effect on tool wear. Int. J. Mach. Tools Manuf. 2004, 24, 327-334.

6. Li, X. On-line detection of the breakage of small diameter drills using current signature wavelet transform, Int. J. Mach. Tools Manuf. 1999, 39, 1, 157-164.

7. Kim, H.Y.; Ahn, J.H.; Kim, S. H.; Takata, S. Real-time drill wear estimation based on spindle motor power. Journal of Materials Processing Technology. 2002, 124, 267-273.

8. Khajavi, A. N.; Komanduri, R. Frequency and time domain analyses of sensor signals in drilling, part 1: correlation with drill wear. Int. J. Mach. Tools Manuf. 1995, 35, 6, 775-793.

9. Thangaraj, A.; Wright, P.K. Computer-assisted prediction of drill-failure using in-process measurements of thrust force. Transactions of the ASME, J. of Eng. for Indus. 1988, 110, 192-200. 
10. Jun, M. B.; Ozdoganlar, O. B.; Devor, R. E.; Kapoor, S. G.; Kirchheim, A.; and Schaffner, G. Evaluation of a spindle-based force sensor for monitoring and fault diagnosis of machining operations. Int. J. Mach. Tools Manuf. 2002, 42, 741-751.

11. Jantunen E., A summary of methods applied to tool condition monitoring in drilling, Int. J. Mach. Tools Manuf. 2002, 42, 997-1010.

12. Benardos, P. G.; Vosniakos, G.C. Predicting surface roughness in machining: A review. Int. J. Mach. Tools Manuf. 2003, 43, $8,833-844$.

13. Bhattacharyya, P.; Sengupta, D.; Mukhopadhyay, S.; Chattopadhyay, A. B. On-line tool condition monitoring in face milling using current and power signals. Int. J. of Prod. Res. 2008, 46, 4, 1187-1201.

14. Li, X.; Tso, S. K. Drill wear monitoring based on current signals. Wear. 1999, 231, 172-178.

15. Luis Alfonso Franco-Gasca.; Gilberto Herrera-Ruiz.; Roc1'o Peniche-Vera.; Rene' de, Jesu's Romero-Troncoso.; Wbaldo Leal-Tafolla.; Sensor less tool failure monitoring system for drilling machines. Int. J. Mach. Tools Manuf. 2006, 46, 381-386

16. Xu, M. J.; New Cutting Technology, Fuhan Press, 2001, chinese.

17. Zhou, Y.; Xue, W. Review of tool condition monitoring methods in milling processes. Int. J. Adv. Manuf. Technol. 2018, 96, 2509-2523.

18. Kunto `glu, M.; Sa ־glam, H. Investigation of Signal Behaviors for Sensor Fusion with Tool Condition Monitoring System in Turning. Measurement. 2020, 108582.

19. Kunto `glu, M.; Aslan, A.; Sa ־glam, H.; Pimenov, D.Y.; Giasin, K.; Mikolajczyk, T. Optimization and Analysis of Surface Roughness, Flank Wear and 5 Different Sensorial Data via Tool Condition Monitoring System in Turning of AISI 5140. Sensors. 2020, 20, 4377.

20. Salgado, D.; Alonso, F. An approach based on current and sound signals for in-process tool wear monitoring. Int. J. Mach. Tools Manuf. 2007. 47, 2140-2152.

21. Szecsi, T. A. DC motor based cutting tool condition monitoring system. J. Mater. Process. Technol. 1999, 92, 350-354.

22. Yip, W.; To, S. Tool life enhancement in dry diamond turning of titanium alloys using an eddy current damping and a magnetic field for sustainable manufacturing. J. Clean. Prod. 2017, 168, 929-939.

23. Kunto `glu, M.; Aslan, A.;Pimenov, D.Y.; Usca, Ü.A.; Salur, E.;Gupta, M.K.; Mikolajczyk, T.; Giasin, K.; Kapłonek, W.; Sharma, S. A Review of Indirect Tool Condition Monitoring Systems and Decision-Making Methods in Turning: Critical Analysis and Trends. Sensors, 2021, 21, 108.

24. Sharma, V. S.; Sharma, S. K.; and Sharma, A.K. Cutting tool wear estimation for turning. J. Intel. Manuf. 2007, 19, 1, 99-108.

25. Xu, C.W.; Xu, T. Experimental tests and empirical models of the cutting force and surface roughness when cutting $1 \mathrm{Cr} 13$ martensitic stainless steel with a coated carbide tool. Adv Mech Eng. Epub ahead of print. 2016, 13.

26. Maranhao, C.; Davim, J. P. Finite element modelling of machining of AISI 316 steel: numerical simulation and experimental validation. Simul Model Pract Th. 2010, 18, 139-156.

27. Huang, P. B.; Zhang, H. J.; Lin, Y. C. Development of a Grey online modeling surface roughness monitoring system in end milling operations. J. Intel. Manuf. 2019a, 30, 4, 1923-1936.

28. Huang, Z.; Zhu, J.; Lei, J.; Li, X.; \& Tian, F. Tool wear predicting based on multi-domain feature fusion by deep convolutional neural network in milling operations. J. Intel. Manuf., 2019b, 31, 4, 953-966.

29. Guzeev, V. I.; Pimenov, D. Y. Cutting force in face milling with tool wear. Russian Engineering Research. 2011, 31, 10, 989993.

30. Pimenov, D. Y.; Guzeev, V. I. Mathematical model of plowing forces to account for flank wear using FME modeling for orthogonal cutting scheme. Int. J. Adv. Manuf. Technol. 2017, 89(9-12), 3149-3159.

31. Pimenov, D Y.; Guzeev, V. I.; Koshin, A. A. Elastic displacement of a technological system in face milling with tool wear. Russian Engineering Research, 2011a, 31, 11, 1105-1109.

32. Wu, Q. Z.; Li, J. H. Fatigue life prediction of notched specimen for 022Cr17Ni12Mo2 stainless steel. Mat Mech Eng. 2015, 39, $55-62$.

33. Xu, Y.Q.; He, Y.; Zou, Z.D. 1Cr18Ni9Ti stainless steel serrated chips instability experimental research. Modular Mach Tool Aut Manuf Tech. 2015, 2, 4-9.

34. Pimenov, D Yu. Mathematical modeling of power spent in face milling taking into consideration tool wear. Journal of Friction and Wear, 2015, 36, 1, 45-48.

35. Mannan, M.; Kassim, A.A.; Jing, M. Application of image and sound analysis techniques to monitor the condition of cutting tools.Pattern Recognit. Lett. 2000, 21, 969-979.

36. Kerr, D.; Pengilley, J.; Garwood, R. Assessment and visualization of machine tool wear using computer vision. Int. J. Adv. Manuf. Technol. 2005, 28, 781-791.

37. Mikołajczyk, T.; Nowicki, K.; Bustillo, A.; Pimenov, D.Y. Predicting tool life in turning operations using neural networks and image processing. Mech. Syst. Signal Process. 2018, 104, 503-513.

38. Barreiro, J.; Castejón, M.; Alegre, E.; Hernández, L. Use of descriptors based on moments from digital images for tool wear monitoring. Int. J. Mach. Tools Manuf. 2008, 48, 1005-1013.

39. Castejón, M.; Alegre, E.; Barreiro, J.; Hernández, L. On-line tool wear monitoring using geometric descriptors from digital images. Int. J. Mach. Tools Manuf. 2007, 47, 1847-1853. 
40. Das, S. R.; Panda, A.; Dhupal, D. Hard turning of AISI 4340 steel using coated carbide insert: Surface roughness, tool wear, chip morphology, and cost estimation. Materials Today, 2018, 5, 6560-6569.

41. Halim, N. H. A.; Haron, C. H. C.; Ghani, J. A.; Azhar, M. F. Tool wear and chip morphology in high-speed milling of hardened Inconel718 under dry and cryogenic $\mathrm{CO}_{2}$ conditions. Wear. 2019, 426-427, 1683-1690.

42. Ning, Y.; Rahman, M.; and Wong, Y. S. Investigation of chip formation in high-speed end milling. J. Mate. Proc. Tech., 2001, 113, 1-3, 360-367.

43. Chinchanikar, S.; Choudhury, S. K. Machining of hardened steel-experimental investigations, performance modeling and cooling techniques: a review. Int. J Mach Tool Manuf. 2015, 89, 95-109.

44. Diniz, A. E.; Machado, A. R.; Corrêa, J. G. Tool wear mechanisms-in the machining of steels and stainless steels. Int. J. Adv. Manuf. Tech. 2016, 87, 3157-3168

45. Zhang, S. J.; Li, F. J.; Deng, X.; and Li, Y. S., Investigation on Diffusion Wear During High-Speed Machining Ti-6Al-4V Alloy with Straight Tungsten Carbide Tools. Int. J. of Adv. Manuf. Tech. 2009, 44, 1-2, 17-25.

46. Jiménez, A.; Arizmendi, M.; \& Sánchez, J. M., Extraction of tool wear indicators in peck-drilling of Inconel 718. Int J Adv Manuf Technol, 2021. https://doi.org/10.1007/s00170-021-07058-7.

47. Buderus Corporation, Handbook of Plastic mold Steels, 2004.

48. Xu, M. J., New Cutting Technology, Fuhan Press, 2001, Chinese.

49. Mitsubishi Tool Co., Ltd., catalog of cutting tools, technical information.

50. Chen, S. H.; Gao, M. S., Study on the Influence of Multi-Sensor and Chip Characteristics Fusion on Tool Life, Master Thesis, National Chin-Yi University of Technology, 2019, Taichung County, Taiwan.

51. Chen, S. H.; Luo, Z. R., Study of using cutting chip color to the tool wear prediction. Int. J. Adv. Manuf. Technol. 2020, 109, 823-839. https://doi.org/10.1007/s00170-020-05354-2

52. Chen, S. H.; Gao, M. S., Method for predicting tool wear with chip color, Patent I649551, 2019.

53. Baardseth, P.; Skrede, G.; Naes, T.; Thomassen, M. S.; Iversen, A.; and Kaaber, L., A Comparison of CIE (1976) L*a*b* values obtained from two different instruments on several food commodities. J. Food Sci. 1988, 53, 1737-1742.

54. Xu C. W.; Dou J. M.; Chai Y.; Li H.; Shi Z.; and Xu J. The relationships between cutting parameters, tool wear, cutting force and vibration. Adv. in Mech. Engin. 2018, 10, 1, 1-14.

55. Zhu, H. B . Influencing factors of milling vibration based on cutting parameters and tool wear. Mech. Res. Appl. 2015, 28, 57-59.

56. Andres B.; Danil Y.; Pimenov M.; Mia W. K. Machine-learning for automatic prediction of flatness deviation considering the wear of the face mill teeth. J. Intel. Manuf. 2021, 32, 895-912.

57. Wu, S. M.; Ermer, D. S.; Hill, W. J. An Exploratory Study of Taylor's Tool-Life Equation by Power Transformations, J. Eng. Ind. ,1996, 88, 1, 81-89. https://doi.org/10.1115/1.3670898.

58. Kronenberg, M. Replacing the Taylor formula by a new tool life equation. Int. J. of Mac. Tool Des. and Res. 1970, 10, $2,193-202$. 